\title{
Intestinal absorption characteristics of imperialine: in vitro and in situ assessments
}

\author{
Qing LIN ${ }^{1}$, Li-qin $\mathrm{LING}^{2}$, Ling GUO ${ }^{1}$, Tao GONG ${ }^{1}$, Xun SUN ${ }^{1}$, Zhi-rong ZHANG ${ }^{1, *}$ \\ ${ }^{1}$ Key Laboratory of Drug Targeting and Drug Delivery Systems, Ministry of Education, West China School of Pharmacy, Sichuan \\ University, Chengdu 610041, China; ${ }^{2}$ West China School of Medicine/West China Hospital, Sichuan University, Chengdu 610041, China
}

\begin{abstract}
Aim: Imperialine is an effective compound in the traditional Chinese medicine chuanbeimu (Bulbus Fritillariae Cirrhosae) that has been used as antitussive/expectorant in a clinical setting. In this study we investigated the absorption characteristics of imperialine in intestinal segments based on an evaluation of its physicochemical properties.

Methods: Caco-2 cells were used to examine uptake and transport of imperialine in vitro, and a rat in situ intestinal perfusion model was used to characterize the absorption of imperialine. The amount of imperialine in the samples was quantified using LC-MS/MS. Results: The aqueous solubility and oil/water partition coefficient of imperialine were determined. This compound demonstrated a relatively weak alkalinity with a $\mathrm{pK}_{\mathrm{a}}$ of $8.467 \pm 0.028$. In Caco-2 cells, the uptake of imperialine was increased with increasing $\mathrm{pH}$ in medium, but not affected by temperature. The apparent absorptive and secretive coefficient was $(8.39 \pm 0.12) \times 10^{-6} \mathrm{~cm} / \mathrm{s}$ and $(7.78 \pm 0.09) \times 10^{-6} \mathrm{~cm} / \mathrm{s}$, respectively. Furthermore, neither the P-glycoprotein inhibitor verapamil nor Niemann-Pick C1-Like 1 transporter inhibitor ezetimibe affected the absorption and secretion of imperialine in vitro. The in situ intestinal perfusion study showed that the absorption parameters of imperialine varied in 4 intestinal segments (duodenum, jejunum, ileum and colon) with the highest ones in the colon, where a greater number of non-ionized form of imperialine was present.

Conclusion: The intestinal absorptive characteristics of imperialine are closely related to its physicochemical properties. The passive membrane diffusion dominates the intestinal absorption of imperialine.
\end{abstract}

Keywords: imperialine; chuanbeimu; traditional Chinese medicine; antitussive/expectorant; physicochemical property; absorption; transport; Caco-2 cells; intestinal perfusion

Acta Pharmacologica Sinica (2015) 36: 863-873; doi: 10.1038/aps.2015.27; published online 8 Jun 2015

\section{Introduction}

Bulbus Fritillariae Cirrhosae ("Chuanbeimu" in Chinese), a traditional Chinese medicine (TCM), has been used as an antitussive and expectorant in China and other Asian countries for centuries ${ }^{[1]}$. In fact, imperialine is one of the main effective compounds in Chuanbeimu and has the potential to be used as an antitussive/expectorant in a clinical setting ${ }^{[2]}$. It is believed that oral administration is most likely preferred over intravenous administration, as oral dosing leads to obvious improved patient compliance ${ }^{[3]}$. However, the data regarding imperialine are far from sufficient to advance the compound to clinical research for oral administration.

A previous study ${ }^{[4]}$ showed that the oral bioavailability of imperialine could be as high as $30 \%-50 \%$, but how this molecule was affected by physicochemical and physiological factors was unknown.

\footnotetext{
* To whom correspondence should be addressed.

E-mail zrzzl@vip.sina.com

Received 2014-10-02 Accepted 2015-02-05
}

Like most alkaloids containing a tertiary amino group, imperialine undergoes $\mathrm{pH}$-dependent hydrolysis of this group (Figure 1). A relatively high $\mathrm{pH}$ typically leads to a greater number of non-ionized molecules and a lower overall solubility. Thus, the $\mathrm{pH}$, which varies in different intestinal segments, is one of the crucial factors affecting the absorption of acidic or alkaline drugs ${ }^{[5]}$. Due to the unknown properties of imperialine under different conditions, we undertook a study of the compound's physicochemical properties, including its solubility, $n$-octanol/water partition coefficient $(P)$ and ionization constant $\left(\mathrm{p} K_{\mathrm{a}}\right)$.

In addition to the physicochemical factors mentioned above, physiological factors can also influence the bioavailability of imperialine. One of the popularly accepted and widely used in vitro systems for transport studies is the Caco- 2 cell monolayer ${ }^{[6,7]}$. These cells, originating from a human colonic adenocarcinoma line, differentiate spontaneously to resemble intestinal enterocytes in morphology and function ${ }^{[8]}$. In the past century, Caco-2 has become an FDA approved model for bioequivalence and is widely used in transport stud- 

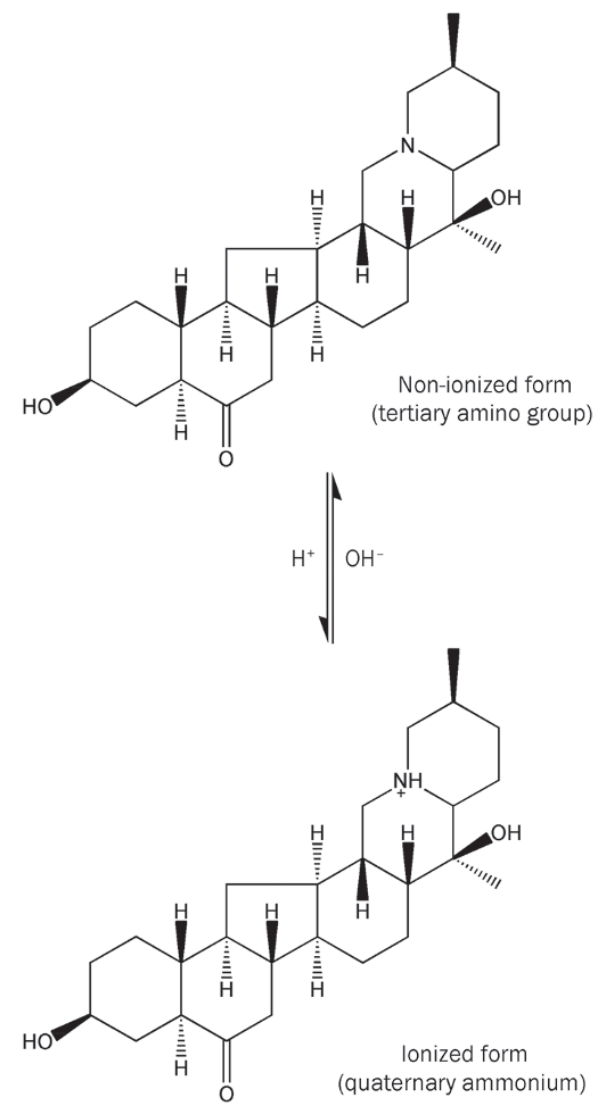

Figure 1. The chemical structure of imperialine.

ies. Dozens of transporters involved in drug uptake and efflux have been found to be expressed in Caco-2 cells, such as P-glycoprotein (P-gp) $)^{[9]}$ and the Niemann-Pick C1-Like 1 $\left(\mathrm{NPC}_{1} \mathrm{~L}_{1}\right)$ transporter ${ }^{[10,11]}$. However, in vitro models provide limited and occasionally inaccurate information. Thus, the combination of in vitro models with in situ approaches can provide experimental conditions that are more comprehensive than those encountered following oral administration, with decreased sensitivity to $\mathrm{pH}$ variations. This is because the microenvironment in the intestinal segments is more closely replicated $^{[12,13]}$. Furthermore, in situ techniques maintain an intact blood supply to the intestine and can be used to evaluate the influence of clearance pathways, such as enzymes and transporters present within the gut. In addition, the expression of drug metabolic enzymes and transporters differs along the intestinal tract, thereby affecting drug permeability in the various segments ${ }^{[14]}$. $\mathrm{NPC}_{1} \mathrm{~L}_{1}$ is abundantly expressed in the jejunum and proximal ileum and is specifically located adjacent to the brush border membrane of intestinal enterocytes, where cholesterol absorption takes place ${ }^{[10]}$. By contrast, P-gp is located in nearly the whole intestinal segment. Single-pass intestinal perfusion (SPIP), with little mechanical injury to the isolated gut, is a good choice for investigating drug absorption in situ. In addition, it has been reported that oral drug absorption in rats closely correlates with that measured in human beings ${ }^{[15]}$. Thus, it is likely that intestinal perfusion studies conducted in rats, combined with studies using the Caco-2 cell model, will more precisely predict the absorption of an oral dose in humans than would an exclusively in vitro model.

To establish a foundation for better understanding the oral absorption and transport features of imperialine, we investigated its physicochemical properties and absorption characteristics in intestinal segments in the current study.

\section{Materials and methods Chemicals and reagents}

Imperialine (purity $>98.0 \%$ ) was obtained from the National Institute for the Control of Pharmaceutical and Biological Products (Beijing, China). Heat-inactivated fetal bovine serum (FBS) and Dulbecco's modified Eagle's medium (DMEM) containing $25 \mathrm{mmol} / \mathrm{L} D$-glucose, $25 \mathrm{mmol} / \mathrm{L}$ HEPES, $44 \mathrm{mmol} / \mathrm{L}$ $\mathrm{NaHCO}_{3}$, non-essential amino acid solution, $L$-glutamine and penicillin-streptomycin were purchased from Gibco Laboratory (Invitrogen Co, Grand Island, NY, USA). A 0.25\% trypsin-0.02\% EDTA solution was obtained from Nanjing KeyGEN Biotech Co Ltd (Nanjing, Jiangsu, China), and Hanks' balanced salt solution (HBSS, containing $137 \mathrm{mmol} / \mathrm{L} \mathrm{NaCl}, 5.36$ $\mathrm{mmol} / \mathrm{L} \mathrm{KCl}, 0.44 \mathrm{mmol} / \mathrm{L} \mathrm{KH}_{2} \mathrm{PO}_{4}, 0.34 \mathrm{mmol} / \mathrm{L} \mathrm{Na}_{2} \mathrm{PO}_{4}, 1$ $\mathrm{mmol} / \mathrm{L} \mathrm{CaCl}, 1 \mathrm{mmol} / \mathrm{L} \mathrm{MgCl}_{2}$, and $5.6 \mathrm{mmol} / \mathrm{L}$ glucose) was purchased from Beijing Solarbio Science \& Technology Co Ltd (Beijing, China). Verapamil was obtained from Aladdin Chemistry Co Ltd (Shanghai, China). HPLC-grade acetonitrile and $n$-octanol were purchased from Sigma-Aldrich (St Louis, MO, USA), and LC-grade formic acid was obtained from Tedia (Cincinnati, OH, USA). Ultra-pure water for the liquid chromatography (LC) mobile phase was prepared in house using a Milli-Q system (Millipore, Bedford, MA, USA). All other reagents were of analytical grade.

\section{Quantitative determination of imperialine}

In this study, we used liquid chromatography coupled with tandem mass spectrometry (LC-MS/MS) to quantify the imperialine levels in the samples. The LC-MS/MS system consisted of a Rapid Resolution Liquid Chromatography system (1200 series, Agilent Technologies, Santa Clara, CA, USA) equipped with an SL autosampler, a degasser and an SL binary pump. An Agilent 6140 triple-quadrupole mass spectrometer with electrospray ionization (ESI) interface was controlled using B01.03 software for qualitative analysis and B01.04 software for quantification.

The MS conditions were adjusted as previously reported ${ }^{[4]}$. RP-LC separation was performed on a Diamonsil ODS column $(100 \mathrm{~mm} \times 4.6 \mathrm{~mm}, 3 \mu \mathrm{m})$ with a corresponding guard column (ODS, $5 \mu \mathrm{m})$. The mobile phase consisted of (A) $0.1 \%(v / v)$ aqueous formic acid and (B) acetonitrile, and the flow rate was $0.4 \mathrm{~mL} / \mathrm{min}$. The following gradient elution was used: $0.0-1.5$ $\min , 10.0 \% \rightarrow 90.0 \% \mathrm{~B}$; $1.5-2.5 \mathrm{~min}, 90.0 \% \rightarrow 10.0 \% \mathrm{~B}$; $2.5-4.0$ min, $10.0 \% \mathrm{~B}$. The column was maintained at $30^{\circ} \mathrm{C}$, and the autosampler tray was kept at $20^{\circ} \mathrm{C}$. An aliquot of $1 \mu \mathrm{L}$ of solution was injected into the LC-MS/MS system for analysis. 
Determination of physicochemical properties Measurement of equilibrium solubility

We adopted the miniaturized shake-flask solubility method to determine the equilibrium solubility of imperialine. Pure water and a series of phosphate buffered saline (PBS) solutions with increasing $\mathrm{pH}$ values $(\mathrm{pH}$ 2.0, 3.0, 4.0, 5.0, 5.8, 6.5, 6.8, 7.0, $7.4,7.8$, and 8.5) were prepared according to Pharmacopoeia of China (Ch.P $)^{[16]}$. The $\mathrm{pH}$ of the buffer solutions was precisely measured using a $\mathrm{pH}$ meter with a combined $\mathrm{Ag} / \mathrm{AgCl}$ glass electrode (FiveStar, Switzerland).

An excess of imperialine was added to $2 \mathrm{~mL}$ water or PBS at varying $\mathrm{pH}$ levels in a 5-mL Eppendorf (EP) tube, and the resulting suspension was shaken at $100 \mathrm{r} / \mathrm{min}$, at $37^{\circ} \mathrm{C}$ for 24 $\mathrm{h}$ in a thermostated shaking incubator (17-C-1, Taicang Experimental Equipment Group Ltd, China). The values obtained were the averages of triplicate measurements. The sample solutions were filtered through a $0.45-\mu \mathrm{m}$ hydrophilic membrane (Tianjin Heng' ao Technological Industry Group Ltd, Tianjin, China), and the subsequent filtrates were collected. After dilution to the desired concentration range in acetonitrile, $1-\mu \mathrm{L}$ aliquots were injected into the LC-MS/MS system for analysis.

\section{Measurement of the n-octanol/water partition coefficient}

The $\log P$ of imperialine was determined using the shake-flask technique. A 2-mL aliquot of pure water or PBS (with different $\mathrm{pH}$ values) saturated with n-octanol was added to $2 \mathrm{~mL}$ imperialine-saturated n-octanol-saturated PBS in a $10-\mathrm{mL}$ EP tube. As described previously ${ }^{[17]}$, the two phases were mutually equilibrated by shaking in a thermostated shaking incubator at a speed of $100 \mathrm{r} / \mathrm{min}$ and a temperature of $37^{\circ} \mathrm{C}$ for $12 \mathrm{~h}$. The tubes were centrifuged at $6000 \times g$ for $5 \mathrm{~min}$, and the aqueous and organic phases were collected. The aqueous sample solutions were then filtered through a $0.45-\mu \mathrm{m}$ hydrophilic membrane, and the organic solutions were filtered through a 0.45- $\mu \mathrm{m}$ hydrophobic membrane (Tianjin Heng'ao Technological Industry Group Ltd, Tianjin, China). The resulting filtrates were diluted to the desired concentration range in acetonitrile, and $1-\mu \mathrm{L}$ aliquots were injected into the LC-MS/MS system for analysis. Each $\log P$ value reported was the average of triplicate measurements. The $n$-octanol/water partition coefficient was calculated using Eq (1),

$$
P=\frac{C_{o}}{C_{w}}
$$

Here, $C_{\mathrm{o}}(\mu \mathrm{g} / \mathrm{mL})$ represents the concentration of imperialine in the organic phase, and $C_{w}(\mu \mathrm{g} / \mathrm{mL})$ represents the concentration of imperialine in the aqueous phase.

The $\log P$ was plotted against the $\mathrm{pH}$, and the linear regression equation and correlation coefficient were calculated using a weighted $\left(1 / x^{2}\right)$ least-squares linear regression method.

\section{Measurement of the ionization constant}

The $\mathrm{p} K_{\mathrm{a}}$ can be measured spectrophotometrically using an acid-base indicator (the spectrophotometric indicator method), which yields accurate results using equipment available in chemistry labs. In the current study, we chose $p$-nitrophenol as the indicator. The method was validated in this study by determining the $\mathrm{p} K_{\mathrm{a}}$ of $p$-nitrophenol and comparing the results to those previously reported (Supplementary Information S1).

Imperialine (B) solutions with different concentrations were prepared in triplicate, and $5 \times 10^{-5} \mathrm{~mol} / \mathrm{L}$ hydrochloride was then added to the solution to partially form imperialine hydrochloride (S). Then, p-nitrophenol was added to each solution to yield a final concentration of $5 \times 10^{-5} \mathrm{~mol} / \mathrm{L}$. The absorbance was obtained at the selected wavelength $(\lambda)$ of $401 \mathrm{~nm}$ using water as a blank. The $\mathrm{p} K_{\mathrm{a}}$ of imperialine was calculated using $\mathrm{Eq}(2)$.

$$
\mathrm{p} K_{\mathrm{a}}^{\mathrm{T}}=\mathrm{p} K_{\mathrm{a}}^{\mathrm{T}}(\operatorname{Int})-\lg \frac{[\mathrm{B}]}{[\mathrm{S}]}+\lg \frac{A-A_{1}}{A_{2}-A}+2 \lg \gamma
$$

The $\gamma$ was calculated according to the Debye-Huckel Formula, Eq (3),

$$
\lg \gamma=-\frac{0.5115 Z^{2} \sqrt{I}}{1+1.5 \sqrt{I}}
$$

where $I$ represents the ionic strength of the solution, and $Z$ represents the charge number of the ion.

\section{Cell culture}

The Caco-2 cell line, originating from the American Type Culture Collection, was obtained from Nanjing KeyGen Biotech Co Ltd (Nanjing, China). The cells were grown routinely in 25- $\mathrm{cm}^{2}$ cell culture flasks (Catalog number: 430639; Corning Incorporated, Corning, NY, USA) in DMEM supplemented with 10\% (v/v) FBS, 1\% (v/v) non-essential amino acid solution, $1 \%(\mathrm{~m} / \mathrm{v}) \mathrm{L}$-glutamine and $1 \%(\mathrm{v} / \mathrm{v})$ penicillin-streptomycin (10 000 units/mL penicillin; $10000 \mu \mathrm{g} / \mathrm{mL}$ streptomycin) in a $\mathrm{CO}_{2}$ incubator (MCO-15AC, SANYO, Japan) with an atmosphere of $5 \% \mathrm{CO}_{2}$, a temperature of $37^{\circ} \mathrm{C}$ and a relative humidity of $90 \%$. The medium was replaced every other day after incubation. When the cells reached $80 \%-90 \%$ confluence, they were passaged at a ratio of $1: 4$ using $0.25 \%$ trypsin- $0.02 \%$ EDTA.

For the uptake experiments, the cells were seeded at a density of $5 \times 10^{4}$ cells $/ \mathrm{cm}^{2}$ with $1 \mathrm{~mL}$ DMEM medium in 12-well tissue culture plates (Catalog No: 3415, Corning Incorporated, Corning, NY, USA) ${ }^{[18]}$. The medium in each well was replaced every other day for the first week after seeding, after which it was replaced every day. Cells with an integrated cell-growing surface $15 \mathrm{~d}$ post-seeding were used for the uptake experiments.

For the transport experiments, the cells were seeded at a density of $5 \times 10^{4}$ cells $/ \mathrm{cm}^{2}$ with $0.5 \mathrm{~mL}$ DMEM medium onto the inserts of 12-well Costar Transwell ${ }^{\circledR}$ plates (Catalog № 3460, Corning Incorporated, Corning, NY, USA $)^{[18]}$, where the insert possessed a polyester (PET) membrane with a pore size of $0.4 \mu \mathrm{m}$, a membrane area of $1.12 \mathrm{~cm}^{2}$ and a nominal pore density of $4 \times 10^{6}$ pores $/ \mathrm{cm}^{2}$. The media in the insert (apical side, $0.5 \mathrm{~mL}$ ) and in the well (basolateral side, $1.5 \mathrm{~mL}$ ) were changed every other day for the first week after seed- 
ing and then changed every day. The Caco- 2 cell monolayers were used for experiments $21 \mathrm{~d}$ after seeding. Cells passaged between 30 and 34 times were used. The quality of the monolayers grown on the PET membranes was assessed by the transepithelial electrical resistance (TEER) of the monolayer and detected with a Millicell-ERS apparatus (ERS0001, Millipore, USA) at $37^{\circ} \mathrm{C}$. Only those monolayers possessing TEER values higher than $1000 \Omega \cdot \mathrm{cm}^{2}$ were used.

\section{Imperialine uptake and transport studies Preparation of the test solutions}

Imperialine was first dissolved in DMSO as a stock solution and then diluted in HBSS ( $\mathrm{pH} 7.4$ ) to yield final concentrations of $1,2,5,10,20,50$, and $100 \mu \mathrm{g} / \mathrm{mL}$. For the $\mathrm{pH}$ course test, the stock solution was diluted in HBSS at different $\mathrm{pH}$ values (5.5, 6.0, 6.5, 7.0, and 7.4) to obtain a nominal concentration of $10 \mu \mathrm{g} / \mathrm{mL}$. For the inhibition studies, the stock solution was diluted in HBSS containing verapamil $(20 \mu \mathrm{g} / \mathrm{mL}, \mathrm{P}$-gp inhibitor) or Ezetimibe $\left(20 \mu \mathrm{g} / \mathrm{mL}, \mathrm{NPC}_{1} \mathrm{~L}_{1}\right.$ inhibitor) to yield final imperialine concentrations of 2,10 , and $50 \mu \mathrm{g} / \mathrm{mL}$. The final DMSO concentration did not exceed $1 \%$. The imperialine in HBSS was validated to be stable in cell tests (Supplementary Information S2).

\section{Caco-2 cell uptake study}

The uptake of imperialine by the Caco-2 cells was studied in wells containing cells that had been cultured for $15 \mathrm{~d}$ after seeding. The growing cell surface was gently washed twice with HBSS (pH 7.4). Afterward, the wells were preincubated with HBSS at $37^{\circ} \mathrm{C}$ in a thermostated shaking incubator for 20 $\min ^{[19]}$. For the inhibition studies, the wells were preincubated in HBSS containing $20 \mu \mathrm{g} / \mathrm{mL}$ verapamil at $37^{\circ} \mathrm{C}$ for $20 \mathrm{~min}$. Each value obtained in this section was an average of triplicate measurements.

\section{Time course of the imperialine uptake}

To measure the imperialine uptake, $1 \mathrm{~mL}$ HBSS containing 10 $\mu \mathrm{g} / \mathrm{mL}$ imperialine was added to the cells in the wells. The wells were then incubated at $37^{\circ} \mathrm{C}$ for $0.5,1,1.5$, or $2 \mathrm{~h}$. After the incubation period, the drug-containing HBSS was removed and $4{ }^{\circ} \mathrm{C}$ HBSS was added to terminate cell uptake. The cell surface was quickly washed three times with HBSS. After the addition of normal saline (NS, $0.9 \% \mathrm{NaCl}$ ), the cells were lysed by repeated freeze-thaw cycles until the cells were completely ruptured. The ruptured cells were spun down and collected. Another aliquot of NS was added to wash the well surfaces, and the ruptured cell-containing NS was collected to obtain a ruptured cell suspension. Some of the suspension, after appropriate dilution by NS, was pretreated by adding a 4-fold volume of acetonitrile for protein precipitation. An aliquot of $1 \mu \mathrm{L}$ supernatant was injected into the LC-MS/MS system for the determination of imperialine after centrifugation $(12000 \times g$ for $10 \mathrm{~min}$ ) and filtration (through a $0.22-\mu \mathrm{m}$ hydrophobic membrane). Another part of the suspension was used for protein determination with the Bradford Method Protein Assay Kit (Catalog №: KGA803, Nanjing KeyGEN Biotech Co Ltd,
China).

\section{The effect of $\mathrm{pH}$ on imperialine uptake}

Samples containing $1 \mathrm{~mL}$ of $10 \mu \mathrm{g} / \mathrm{mL}$ imperialine-HBSS at different $\mathrm{pH}$ values $(5.5,6.0,6.5,7.0$, and 7.4$)$ were added to preincubated cell wells. The wells were then incubated at $37^{\circ} \mathrm{C}$ for $1 \mathrm{~h}$. The remaining post-treatment was performed as described in the section Time course of imperialine uptake.

\section{The effect of concentration on imperialine uptake}

Aliquots (1 mL HBSS) containing imperialine at different concentrations $(1,2,5,10,20,50$, and $100 \mu \mathrm{g} / \mathrm{mL})$ were added to the preincubated cell wells. The wells were then incubated at $37^{\circ} \mathrm{C}$ for $1 \mathrm{~h}$. The post-treatment was performed as described in the section Time course of imperialine uptake.

\section{The effect of temperature on imperialine uptake}

$1 \mathrm{~mL}$ of HBSS containing imperialine at different concentrations $(2,10$, and $50 \mu \mathrm{g} / \mathrm{mL})$ was added to the preincubated cell wells. The wells with different imperialine concentrations were then respectively incubated at 4,25 , and $37^{\circ} \mathrm{C}$ for $1 \mathrm{~h}$. The post-treatment was performed as described in the section Time course of imperialine uptake.

The effect of the P-gp inhibitor on imperialine uptake

Treatments of $1 \mathrm{~mL}$ imperialine $(2,10$, and $50 \mu \mathrm{g} / \mathrm{mL})$-HBSS (containing $20 \mu \mathrm{g} / \mathrm{mL}$ verapamil) were added to the preincubated cell wells. The wells were then incubated at $37^{\circ} \mathrm{C}$ for $1 \mathrm{~h}$. The post-treatment was performed as described in the section Time course of imperialine uptake.

\section{The effect of the NPC1L1 inhibitor on imperialine uptake}

Treatments of $1 \mathrm{~mL}$ imperialine $(2,10$, and $50 \mu \mathrm{g} / \mathrm{mL})$-HBSS (containing $20 \mu \mathrm{g} / \mathrm{mL}$ Ezetimibe) were added to the preincubated cell wells. The wells were then incubated at $37^{\circ} \mathrm{C}$ for $1 \mathrm{~h}$. The post-treatment was performed as described in the section Time course of imperialine uptake.

\section{Caco-2 cell transport study}

The transport of imperialine across the Caco-2 cell monolayers was studied using 21-d post-seeding monolayers as described in the section Cell Culture. The monolayers were gently washed twice with HBSS ( $\mathrm{pH}$ 7.4). After washed, the monolayers were preincubated in HBSS, both on the apical (AP) and on the basolateral (BL) sides, at $37^{\circ} \mathrm{C}$ in a thermostated shaking incubator for $20 \mathrm{~min}^{[18]}$. For the P-gp inhibition study, the monolayers were preincubated in HBSS containing $20 \mu \mathrm{g} / \mathrm{mL}$ Verapamil (in the donor chamber) and HBSS (in the receptor chamber); for the $\mathrm{NPC}_{1} \mathrm{~L}_{1}$ transporter inhibition, the monolayers were preincubated in HBSS containing $20 \mu \mathrm{g} / \mathrm{mL}$ Ezetimibe (in the donor chamber) and HBSS (in the receptor chamber). Each value obtained in this section is the average of triplicate measurements.

The effect of the apical $p H$ on imperialine transport

Aliquots of $0.5 \mathrm{~mL}$ HBSS (pH 5.5, 6.0, 6.5, 7.0, and 7.4) con- 
taining $10 \mu \mathrm{g} / \mathrm{mL}$ imperialine were added to the Transwell ${ }^{\circledR}$ AP side, and $1.5 \mathrm{~mL}$ HBSS ( $\mathrm{pH} 7.4$ ) was added to the BL side. The monolayers were incubated at $37^{\circ} \mathrm{C}$ and placed in a thermostated shaking incubator at a speed of $60 \mathrm{r} / \mathrm{min}$ during the transport process to minimize the influence of the aqueous boundary layer. Samples were taken from the receptor chamber (BL side) at $0,30,60,90$, and $120 \mathrm{~min}$, followed by immediate replacement with the same volume of $37^{\circ} \mathrm{C}$ fresh HBSS. After appropriate dilution by HBSS, a 4-fold volume of acetonitrile was added. The samples were then thoroughly vortexed, and a $1 \mu \mathrm{L}$ aliquot of the test solution (after filtration through a $0.22-\mu \mathrm{m}$ hydrophobic membrane) was injected into the LC-MS/MS system for the measurement of imperialine.

\section{The effect of concentration on imperialine transport}

To measure the AP to BL transport, $0.5 \mathrm{~mL}$ HBSS containing imperialine at different concentrations $(1,2,5,10,20,50$, and $100 \mu \mathrm{g} / \mathrm{mL}$ ) was added to the AP side, and $1.5 \mathrm{~mL}$ HBSS was added to the BL side. The monolayers were incubated at $37^{\circ} \mathrm{C}$ and placed in a thermostated shaking incubator at a speed of $60 \mathrm{r} / \mathrm{min}$ during the transport process. Samples were collected from the receptor chamber (BL side) at 0, 30, 60, 90, and $120 \mathrm{~min}$, followed by immediate replacement with the same volume of $37^{\circ} \mathrm{C}$ fresh HBSS.

For the measurement of BL to AP transport, $1.5 \mathrm{~mL}$ HBSS containing imperialine at different concentrations $(1,2,5,10$, 20,50 , and $100 \mu \mathrm{g} / \mathrm{mL}$ ) was added to the BL side, and 0.5 $\mathrm{mL}$ blank HBSS was added to the AP side. The monolayers were incubated at $37^{\circ} \mathrm{C}$ and placed in a thermostated shaking incubator at a speed of $60 \mathrm{r} / \mathrm{min}$ during the transport process. Samples were collected from the donor chamber (AP side) at $0,30,60,90$, and $120 \mathrm{~min}$, followed by immediate replacement with the same volume of $37^{\circ} \mathrm{C}$ fresh HBSS. The pretreatment of samples prior to LC-MS/MS was performed as described in the section Effect of apical $p H$ on imperialine transport. The transport rate was plotted against the imperialine concentration in HBSS, and the linear regression equation and correlation coefficient were calculated using a weighted $\left(1 / x^{2}\right)$ least-squares linear regression method.

\section{The effect of the P-gp inhibitor on imperialine transport}

For the measurement of AP to BL transport, $0.5 \mathrm{~mL}$ imperialine $(2,10$, and $50 \mu \mathrm{g} / \mathrm{mL}$ )-HBSS (containing $20 \mu \mathrm{g} / \mathrm{mL}$ Verapamil) was added to the AP side, and $1.5 \mathrm{~mL}$ blank HBSS was added to the BL side. For the measurement of BL to AP transport, $1.5 \mathrm{~mL}$ imperialine $(2,10$, and $50 \mu \mathrm{g} / \mathrm{mL}$ )-HBSS (containing $20 \mu \mathrm{g} / \mathrm{mL}$ verapamil) was added to the BL side, and 0.5 mL blank HBSS was added to the AP side. The post-treatment was performed as described in the section Effect of concentration on imperialine transport.

\section{The effect of the NPC $\underline{L}_{1} \underline{L}_{1}$ inhibitor on imperialine transport}

For the measurement of AP to BL transport, $0.5 \mathrm{~mL}$ imperialine $(2,10$, and $50 \mu \mathrm{g} / \mathrm{mL}$ )-HBSS (containing $20 \mu \mathrm{g} / \mathrm{mL}$ Ezetimibe) was added to the AP side, and $1.5 \mathrm{~mL}$ blank HBSS was added to the BL side. For the measurement of BL to AP trans- port, $1.5 \mathrm{~mL}$ imperialine $(2,10$, and $50 \mu \mathrm{g} / \mathrm{mL}$ )-HBSS (containing $20 \mu \mathrm{g} / \mathrm{mL}$ verapamil) was added to the BL side, and 0.5 mL blank HBSS was added to the AP side. The post-treatment was performed as described in the section Effect of concentration on imperialine transport.

\section{Data analysis}

The Caco-2 cell uptake (mg/g) was calculated using Eq (4),

$$
\text { Caco- } 2 \text { cell uptake }(\mathrm{mg} / \mathrm{kg})=\frac{\text { Imperialine uptake }(\mathrm{mg})}{\text { Protein content }(\mathrm{g})}
$$

The apparent permeability coefficient $\left(P_{\text {app }}, \mathrm{cm} / \mathrm{s}\right)$ was calculated using Eq (5),

$$
P_{\mathrm{app}}=\frac{\mathrm{d} Q / \mathrm{d} t}{A C_{0}}
$$

where $\mathrm{d} Q / \mathrm{d} t(\mu \mathrm{g} / \mathrm{s})$ is the drug permeation rate, $A$ is the cross sectional area $\left(1.12 \mathrm{~cm}^{2}\right)$, and $C_{0}(\mu \mathrm{g} / \mathrm{mL})$ is the initial imperialine concentration in the donor compartment.

To compensate for the dilution effect caused by fluid replacement after sampling, the cumulative transport flux $T R_{\text {cum }}(\mu \mathrm{g} / \mathrm{mL})$ was revised using Eq (6).

$$
\mathrm{TR}_{\text {cum }}=A_{\mathrm{n}}+\frac{V_{\mathrm{Sn}}}{V_{\mathrm{R}}} \sum_{i=0}^{n-1} A_{\mathrm{i}}
$$

where $A_{\mathrm{n}}$ and $A_{\mathrm{i}}(\mu \mathrm{g})$ represent the detected transport flux of the nth and ith sample, respectively; $V_{\mathrm{Sn}}(\mathrm{mL})$ represents the sampling volume of the nth sample, and $V_{\mathrm{R}}(\mathrm{mL})$ is the total volume of HBSS in the receptor chamber.

If necessary, the two groups of data could be analyzed by a two-tailed $t$-test to investigate whether they exhibited significant differences.

\section{Single-pass intestinal perfusion in rats}

A prediction of the absorption behavior of imperialine in the human intestine is essential for the preformulation. In vitro assays in Caco-2 cells are routinely used for this purpose. However, in situ techniques combined with in vitro models might provide a more accurate estimation of intestinal absorption of imperialine. In the current study, we evaluated a modified gravimetric method of single-pass intestinal perfusion (SPIP) in the rat. The effective permeability coefficients $\left(P_{\text {eff }}\right)$ for imperialine were therefore determined in rats.

\section{Preparation of working perfusates}

The intestinal perfusion solution was freshly prepared from a Krebs-Ringer (K-R) solution (containing $7.8 \mathrm{~g} / \mathrm{L} \mathrm{NaCl}$, $0.35 \mathrm{~g} / \mathrm{L} \mathrm{KCl}, 0.37 \mathrm{~g} / \mathrm{L} \mathrm{CaCl}_{2}, 1.37 \mathrm{~g} / \mathrm{L} \mathrm{NaHCO}_{3}, 0.32 \mathrm{~g} / \mathrm{L}$ $\mathrm{NaH}_{2} \mathrm{PO}_{4}, 0.02 \mathrm{~g} / \mathrm{L} \mathrm{MgCl}_{2}$, and $1.4 \mathrm{~g} / \mathrm{L}$ glucose) with a certain amount of imperialine stock solution. Perfusates containing imperialine at different concentrations $(1,5$, or $10 \mu \mathrm{g} / \mathrm{mL})$ were thus obtained. For the P-gp inhibition study, $10 \mu \mathrm{g} / \mathrm{mL}$ verapamil was added to perfusate containing $5 \mu \mathrm{g} / \mathrm{mL}$ imperialine. For the $\mathrm{NPC}_{1} \mathrm{~L}_{1}$ inhibition study, $10 \mu \mathrm{g} / \mathrm{mL}$ Ezetimibe was added to the imperialine $(5 \mu \mathrm{g} / \mathrm{mL})$-containing perfusate. The imperialine in the working solutions was determined to 
be sufficiently stable and thus reasonable for use after incubation with an intestinal segment for SPIP (Supplementary Information S2).

\section{Animals and surgery}

The study protocol was approved by the Animal Ethics Committee of Sichuan University (Chengdu, China). Male Sprague-Dawley rats $(200 \pm 20 \mathrm{~g})$ were obtained from the Experimental Animal Center of West China, Sichuan University.

The rats were raised in a controlled environment with a temperature of $23-26^{\circ} \mathrm{C}$, a relative humidity of $40 \%-60 \%$ and a noise level below $60 \mathrm{~dB}$. Light and dark cycles were matched to the rats' natural circadian rhythms for at least 1 week to facilitate their adaptation to the housing conditions. The animals were fasted for $12 \mathrm{~h}$ before surgery, but water was always available.

For surgery, the rats were anesthetized and placed on a warmed pad to maintain normal body temperature under a heat lamp. A midline incision was made in the abdomen. Except for the $\mathrm{NPC}_{1} \mathrm{~L}_{1}$ inhibition study, a small intestinal (duodenal, jejunal or ileal) segment of approximately $10 \mathrm{~cm}$ or a colonic segment of approximately $5 \mathrm{~cm}$ was isolated; for the $\mathrm{NPC}_{1} \mathrm{~L}_{1}$ inhibition study, only jejunal and colonic segments were isolated. The final length of each segment was normalized. Semi-circular incisions were made at each end of the segment, and the lumen was rinsed with NS prewarmed to $37^{\circ} \mathrm{C}$. Both ends were cannulated using rubber tubing with an inner diameter of $2.08 \mathrm{~mm}$, and then ligated.

The perfusates were infused for $5 \mathrm{~min}$ at a flow rate of $1 \mathrm{~mL} / \mathrm{min}$ using a constant-current peristaltic pump (model number: HL-2, Shanghai Qingpu-Huxi Instrument Factory, Shanghai, China). The intestinal segments were then perfused with a test solution at $0.2 \mathrm{~mL} / \mathrm{min}$ for $30 \mathrm{~min}$ to achieve absorption equilibrium and stable outflow rates. Then, a known-mass EP tube with a certain volume of perfusate (containing 1,5 , or $10 \mu \mathrm{g} / \mathrm{mL}$ imperialine) was placed at the inflow point, initiating the intestinal perfusion at a constant flow rate of $0.2 \mathrm{~mL} / \mathrm{min}$. At the other end, the outflow was gathered by an empty EP tube of known mass. Every $10 \mathrm{~min}$, the EP tubes at the inflow and outflow points were simultaneously replaced by brand-new ones with or without perfusate, after which the former ones were weighed to calculate the mass of inflow and outflow. An aliquot of $0.5 \mathrm{~mL}$ perfusate was spiked to weigh the gain in density $(\rho)$ of the in/out perfusate. The final perfusion was performed for a total of $60 \mathrm{~min}$. After that, the tested segment was cut off and placed in NS without any stretch or crimp. The length $(l)$ and width $(2 \pi r, r$ is the inner diameter) of the segments were measured. After the inflow and outflow were diluted to the desired concentration range, a 4-fold volume of acetonitrile was added and the samples were vortexed throughout. After filtration through a 0.22- $\mu$ m hydrophobic membrane, an aliquot of $1 \mu \mathrm{L}$ test solution was injected into the LC-MS/MS system for the determination of imperialine.

The value (for each segment and each perfusate with different concentrations) obtained in this section was the average of at least five rats.

\section{Data analysis}

Because the intestine absorbs not only imperialine but also moisture, the volume of inflow perfusate $\left(Q_{\text {in }}\right)$ and outflow solution $\left(Q_{\text {out }}\right)$ was revised as given by $\mathrm{Eq}(7)$ and $\mathrm{Eq}(8)$, respectively,

$$
\begin{aligned}
Q_{\text {in }} & =\frac{M_{\text {in }}}{\rho_{\text {in }}} \\
Q_{\text {out }} & =\frac{M_{\text {out }}}{\rho_{\text {out }}}
\end{aligned}
$$

where $M_{\text {in }}(\mathrm{g})$ and $M_{\text {out }}(\mathrm{g})$ represent the masses of the inflow and outflow perfusates, respectively, and $\rho_{\text {in }}(\mathrm{g} / \mathrm{mL})$ and $\rho_{\text {out }}$ $(\mathrm{g} / \mathrm{mL})$ represent the densities of the inflow and outflow perfusates, respectively.

The corrected concentration of imperialine [ $C_{\text {out (corrected), }}$ $\mu \mathrm{g} / \mathrm{mL}]$ was calculated as Eq (9),

$$
C_{\text {out (corrected) }}=\frac{C_{\text {out }} Q_{\text {out }}}{Q_{\text {in }}}
$$

where $Q_{\text {in }}(\mathrm{mL})$ was the measured flow entering the intestine and $Q_{\text {out }}(\mathrm{mL})$ was the measured perfusate exit flow (for the specified time interval).

The effective permeability coefficient $\left(P_{\text {eff, }} \mathrm{cm} / \mathrm{min}\right)$, absorption rate constant $\left(K_{a}, \min ^{-1}\right)$ and intestinal absorption amount $\left(M_{\mathrm{a}}, \mu \mathrm{g} / \mathrm{cm}^{2}\right)$ were calculated using Eq (10), Eq (11), and Eq (12), respectively,

$$
\begin{aligned}
P_{\text {eff }} & =\frac{Q_{\text {out }}\left[\frac{C_{\text {in }}}{C_{\text {out (corrected) }}}\right]}{2 \pi r l} \\
K_{\mathrm{a}} & =\frac{\left[1-\frac{C_{\text {out (corrected) }}}{C_{\text {in }}}\right] Q}{\pi r^{2} l} \\
M_{\mathrm{a}} & =\frac{Q\left[C_{\text {in }}-C_{\text {out (corrected) }}\right]}{2 \pi r l}
\end{aligned}
$$

where $C_{\text {in }}(\mu \mathrm{g} / \mathrm{mL})$ and $C_{\text {out (corrected) }}(\mu \mathrm{g} / \mathrm{mL})$ correspond to the inlet and outlet (corrected for volume changes) imperialine concentrations, respectively, while $r(\mathrm{~cm})$ is the intestinal radius and $1(\mathrm{~cm})$ is the length of the isolated segment. $Q(0.2$ $\mathrm{mL} / \mathrm{min}$ ) is the flow rate through the intestinal segment.

If necessary, a two-tailed $t$-test was applied to investigate the statistical difference between two groups of data.

\section{Results}

\section{Physicochemical properties of imperialine}

The precise $\mathrm{pH}$ values of the water and PBS solutions were measured as 2.00, 3.00, 4.03, 5.02, 5.82, 6.48, 6.80, 7.00, $7.39,7.80$, and 8.50 . The apparent solubility of imperialine decreased as the $\mathrm{pH}$ increased (Figure 2A). The ratio of the ionized form to the non-ionized form decreased as the $\mathrm{pH}$ increased.

The apparent $n$-octanol/water partition coefficient $(P)$ of imperialine increased with increasing $\mathrm{pH}$ (Figure 2B). The obtained linear equation of $\log P$ against the $\mathrm{pH}$ of $\mathrm{PBS}$ was 

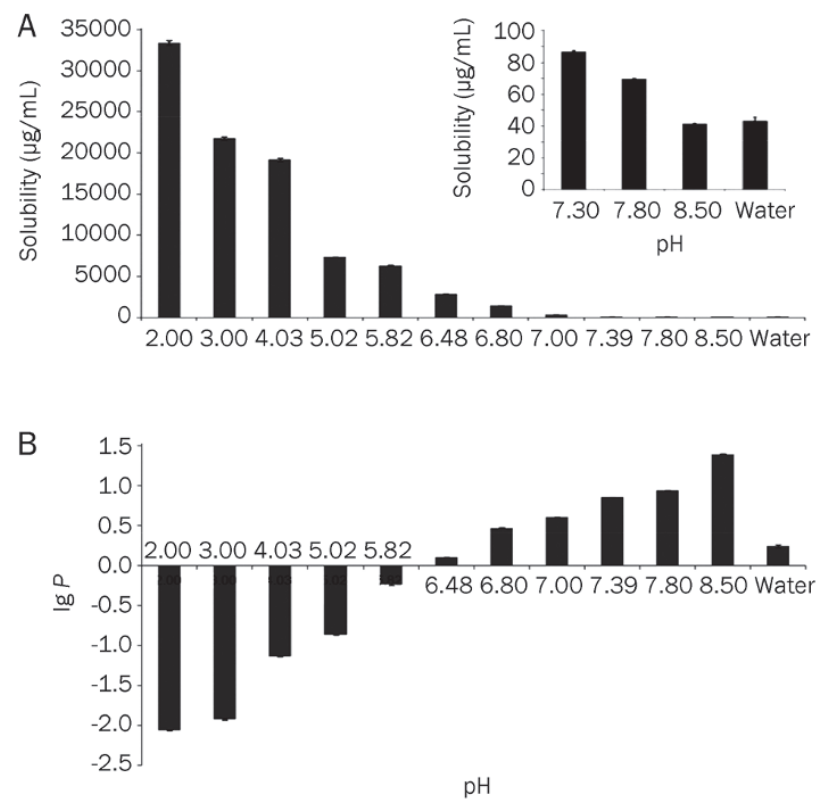

Figure 2. (A) Apparent solubility-pH curve of imperialine $(n=3)$; (B) Partition coefficient-pH curve of imperialine $(n=3)$.

$y=0.5653 x-3.4438, r^{2}=0.9943$, where $y$ represented $\log P, x$ represented the $\mathrm{pH}$ and $r$ represented the correlation coefficient. At $\log P=0$, the $\mathrm{pH}$ was 6.09 , which suggested that imperialine behaved better in terms of solubility in the aqueous phase when the $\mathrm{pH}$ was $<6.09$, while it exerted better solubility in the oil phase when the $\mathrm{pH}>6.09$. Its behavior was consistent with that determined in the section Equilibrium solubility of imperialine.

The measurements are summarized in Table 1 . The calculation was carried out using Eq (2), and the $\mathrm{p} K_{\mathrm{a}}$ of imperialine was determined to be $8.467 \pm 0.028$. This indicates that imperialine was alkaline, which is consistent with the presence of a tertiary amino group in its molecular structure.

Table 1. Measurements for $p K_{a}$ of imperialine ${ }^{a}$. All results are the mean of measurements from three replicates.

\begin{tabular}{lllll}
\hline$[\mathrm{B}] \times 10^{-4}$ & {$[\mathrm{~S}] \times 10^{-5}$} & {$[\mathrm{~B}] /[\mathrm{S}]$} & \multicolumn{1}{c}{$A$} & \multicolumn{1}{c}{$\mathrm{pK}_{\mathrm{a}}{ }^{\top}$} \\
\hline 0.5218 & 5.0000 & 1.0436 & $0.9653 \pm 0.0003$ & $8.467 \pm 0.028$ \\
0.4196 & 5.0000 & 0.8392 & $0.9493 \pm 0.0006$ & \\
0.3174 & 5.0000 & 0.63489 & $0.9424 \pm 0.0002$ & \\
0.2152 & 5.0000 & 0.4305 & $0.9128 \pm 0.0002$ & \\
0.1131 & 5.0000 & 0.2261 & $0.8351 \pm 0.0001$ & \\
\hline
\end{tabular}

${ }^{\mathrm{a}} A_{1}=0.0282, A_{2}=0.9170, \lambda=401 \mathrm{~nm}$.

\section{Uptake characteristics of imperialine in the Caco-2 cells}

\section{Time course of uptake}

The uptake of imperialine $(10 \mu \mathrm{g} / \mathrm{mL})$ in the Caco- 2 cell at 0.5 , $1,1.5$, and $2 \mathrm{~h}$ is displayed in Figure 3A. Among the testing time plots, the Caco-2 cells took up imperialine to the great- est extent at $1 \mathrm{~h}$. Therefore, $1 \mathrm{~h}$ was selected as the incubation time for the following uptake experiment.

\section{The effect of $p H$ on uptake}

As shown in Figure 3B, the Caco-2 cell uptake of imperialine $(10 \mu \mathrm{g} / \mathrm{mL})$ from HBSS at $\mathrm{pH}$ values of 5.5, 6.0, 6.5, 7.0, and 7.4 was tested. The values obtained were $0.17 \pm 0.03,0.26 \pm 0.03$, $0.48 \pm 0.06,0.64 \pm 0.06$, and $1.06 \pm 0.03 \mathrm{mg} / \mathrm{g}$ protein, respectively. The results for the groups $(\mathrm{pH} 5.5,6.0,6.5$, and 7.0) were compared to the results for $\mathrm{pH} 7.4$, and all exhibited significant differences $(P<0.001)$. Therefore, the $\mathrm{pH}$ obviously affected the Caco-2 cell uptake of imperialine. Because the greatest uptake occurred at $\mathrm{pH} 7.4$, a $\mathrm{pH}$ of 7.4 was selected as the optimal $\mathrm{pH}$.

\section{The effect of concentration on uptake}

We measured the Caco-2 cell uptake of imperialine in HBSS at different imperialine concentrations $(1,2,5,10,20,50$, and $100 \mu \mathrm{g} / \mathrm{mL}$ ). The results (Figure 3) show that the uptake of imperialine increased with increasing concentration in a linear manner. The linear regression equation was $y=0.0803 x+0.0459$, $r^{2}=0.9982$, where y represents the uptake amount $(\mathrm{mg} / \mathrm{g}), x$ represents the concentration of imperialine $(\mu \mathrm{g} / \mathrm{mL})$, and $r$ represents the correlation coefficient. As the results showed, the imperialine uptake did not behave like a saturation phenomenon. This suggests that imperialine may have been taken up mainly by passive membrane diffusion.

\section{The effect of temperature on uptake}

We investigated the uptake of imperialine (at concentrations of $2,10$, and $50 \mu \mathrm{g} / \mathrm{mL})$ at different temperatures $\left(4,25\right.$, or $\left.37^{\circ} \mathrm{C}\right)$. The results are shown in Figure 3D. Significant differences were observed between groups with the same imperialine concentration but different temperatures $(P<0.05)$. In addition, imperialine was taken up by the Caco- 2 cells at $4^{\circ} \mathrm{C}$. Although significant differences existed, we believed they were due to the enhanced drug movement and increased membrane fluidity that were physically caused by the temperature increase, instead of the energy-dependence of the process itself.

\section{The effect of the P-gp and NPC $C_{1} \underline{L}_{1}$ inhibitor on uptake}

In the current study, the P-gp inhibitor $(20 \mu \mathrm{g} / \mathrm{mL}$ verapamil) or $\mathrm{NPC}_{1} \mathrm{~L}_{1}$ transporter inhibitor $(20 \mu \mathrm{g} / \mathrm{mL}$ Ezetimibe) was added in the Caco-2 cell uptake studies, and the results are shown in Figure 3E. However, similar uptake was observed in the presence of either the P-gp inhibitor or the $\mathrm{NPC}_{1} \mathrm{~L}_{1}$ transporter inhibitor and in their absence. This finding implied that P-gp was not involved in the efflux of imperialine and that the $\mathrm{NPC}_{1} \mathrm{~L}_{1}$ transporter did not participate in the absorption.

\section{Transport characteristics of imperialine in Caco- 2 cells}

\section{The effect of $\mathrm{pH}$ on transport}

The varying $\mathrm{pH}$ in the apical-side HBSS significantly affected the imperialine transport flux from the apical (AP) to the basolateral (BL) side, as observed in Figure 4A. The cumulative transport was greatest when the apical $\mathrm{pH}$ was 7.4. This result suggested that when imperialine was added to apical HBSS, a 

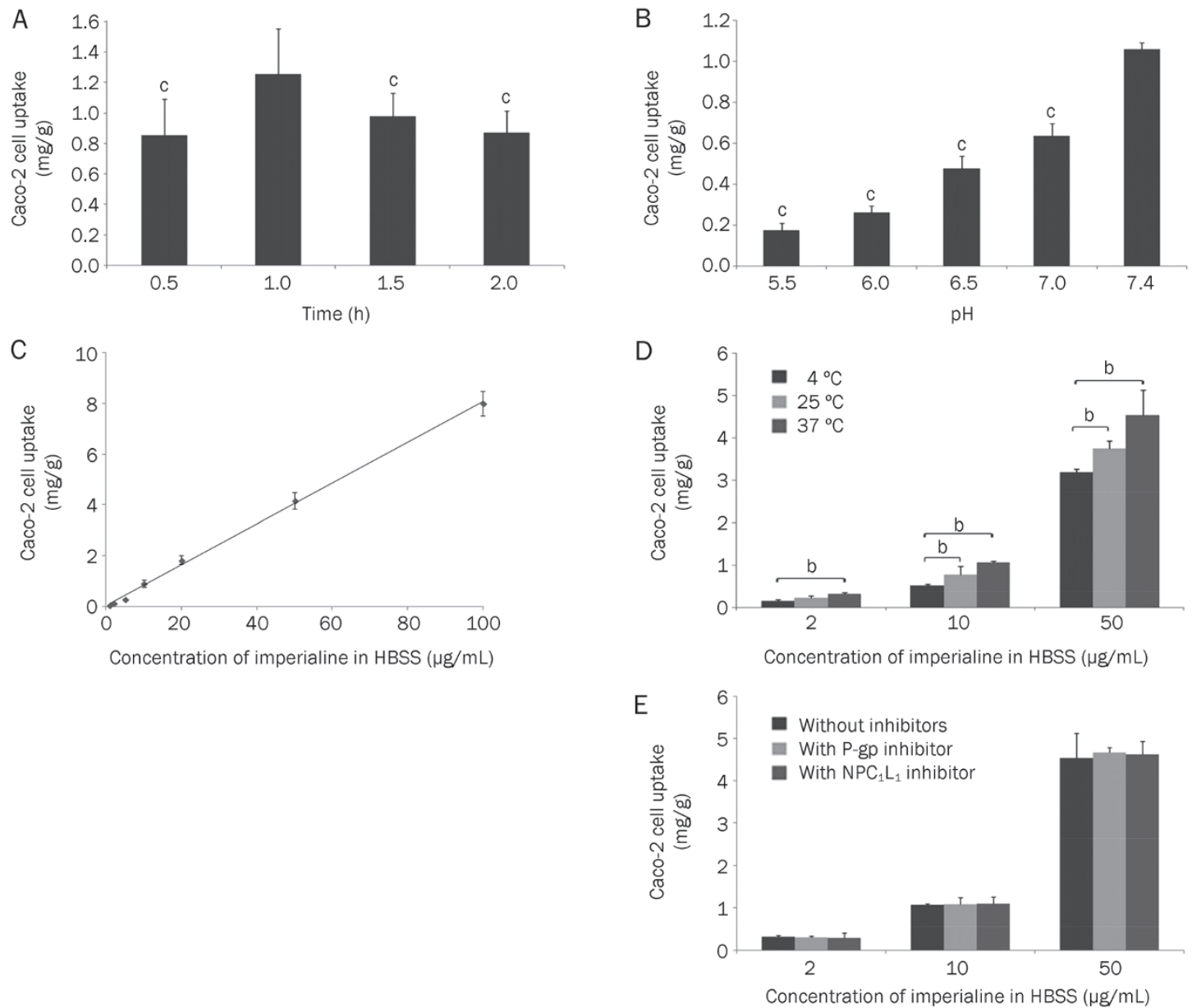

Figure 3. (A) The time course of Caco- 2 cell uptake of imperialine $(n=3){ }^{c}{ }^{c} P<0.01$, compared with $1 \mathrm{~h}$; (B) The effect of $\mathrm{pH}$ on imperialine in Caco-2 cell uptake $(n=3)$. ${ }^{\mathrm{C}} P<0.01$, compared with the $\mathrm{pH} 7.4$ group; (C) The effect of concentration on imperialine in Caco-2 cell uptake ( $\left.n=3\right)$; (D) The effect of temperature on imperialine in Caco-2 cell uptake $(n=3)$ : ${ }^{\mathrm{b}} \mathrm{P}<0.05$; (E) The effect of the P-gp or $\mathrm{NPC}_{1} \mathrm{~L}_{1}$ transporter inhibitor on Caco-2 cell uptake $(n=3)$.

pH of 7.4 was optimal for the following transport experiments.

\section{The effect of concentration on transport}

We measured the absorption ( $\mathrm{AP} \rightarrow \mathrm{BL}$ side) and secretion $(\mathrm{BL} \rightarrow \mathrm{AP}$ side) of imperialine in the Caco-2 cell monolayers, and the resulting data are summarized in Table 2. The transport rate was plotted against the imperialine concentration

Table 2. Transport parameters of imperialine. Mean \pm SD. $n=3$.

\begin{tabular}{ccccc}
\hline $\begin{array}{c}\text { Concen- } \\
\text { tration } \\
(\mu \mathrm{g} / \mathrm{mL})\end{array}$ & $\begin{array}{c}\text { Apical to basolateral side } \\
\left(\times 10^{-6} \mathrm{~cm} / \mathrm{s}\right)\end{array}$ & $\begin{array}{c}\text { Bansport rate } \\
\left(\mathrm{ng} \cdot \mathrm{cm}^{-2} \cdot \mathrm{min}^{-1}\right)\end{array}$ & $\begin{array}{c}\text { Basolateral to apical side } \\
\left(\times 10^{-6} \mathrm{~cm} / \mathrm{s}\right)\end{array}$ & $\begin{array}{c}\text { Transport rate } \\
\left(\mathrm{ng} \cdot \mathrm{cm}^{-2} \cdot \mathrm{min}^{-1}\right)\end{array}$ \\
\hline 1 & $8.42 \pm 0.14$ & $0.505 \pm 0.171$ & $7.87 \pm 1.28$ & $0.472 \pm 0.077$ \\
2 & $8.23 \pm 0.48$ & $0.988 \pm 0.057$ & $7.72 \pm 0.45$ & $0.907 \pm 0.050$ \\
5 & $8.50 \pm 0.36$ & $2.550 \pm 0.109$ & $7.70 \pm 0.30$ & $2.309 \pm 0.090$ \\
10 & $8.22 \pm 0.10$ & $4.934 \pm 0.062$ & $7.63 \pm 0.22$ & $4.451 \pm 0.240$ \\
20 & $8.44 \pm 0.93$ & $9.054 \pm 1.118$ & $7.87 \pm 0.15$ & $9.446 \pm 0.177$ \\
50 & $8.47 \pm 0.42$ & $24.776 \pm 1.265$ & $7.81 \pm 0.26$ & $23.435 \pm 0.784$ \\
100 & $8.49 \pm 1.32$ & $54.448 \pm 8.294$ & $7.84 \pm 0.66$ & $47.033 \pm 3.987$ \\
\hline
\end{tabular}

in HBSS (Figure 4B), and $P_{\text {app }}$ was plotted against concentration (Figure $4 \mathrm{C}$ ). In the concentration range of $1-100 \mu \mathrm{g} / \mathrm{mL}$, both the absorption and the secretion of imperialine were well described by a straight line. The linear regression equation for absorption $(\mathrm{AP} \rightarrow \mathrm{BL})$ was $y=0.5409 x-0.6348, r^{2}=0.9975$, while the equation for secretion $(\mathrm{BL} \rightarrow \mathrm{AP})$ was $y=0.4708 x-0.0655$, $r^{2}=0.9999$. Here, $y$ represents the uptake amount $(\mathrm{mg} / \mathrm{g}), x$ represents the concentration of imperialine $(\mu \mathrm{g} / \mathrm{mL})$ and $r$ represents the correlation coefficient. The $P_{\text {app }}$ of absorption or secretion was basically flat in this concentration range, with an absorptive $P_{\text {app }}$ of $(8.39 \pm 0.12) \times 10^{-6} \mathrm{~cm} / \mathrm{s}$ and a secretive $P_{\text {app }}$ of $(7.78 \pm 0.09) \times 10^{-6} \mathrm{~cm} / \mathrm{s}$. All results in this section corresponded to those in the Caco-2 cell uptake studies.

\section{The effect of $P$-gp and the NPC ${ }_{1} \underline{L}_{1}$ inhibitor on transport}

The effects of verapamil and Ezetimibe on imperialine absorption and secretion were studied. The addition of verapamil or Ezetimibe had no significant influence on either the absorption or the secretion (Table 3). This result further suggested that the transport of imperialine across the Caco- 2 cell monolayers was not regulated by the P-gp or $\mathrm{NPC}_{1} \mathrm{~L}_{1}$ transporters. 

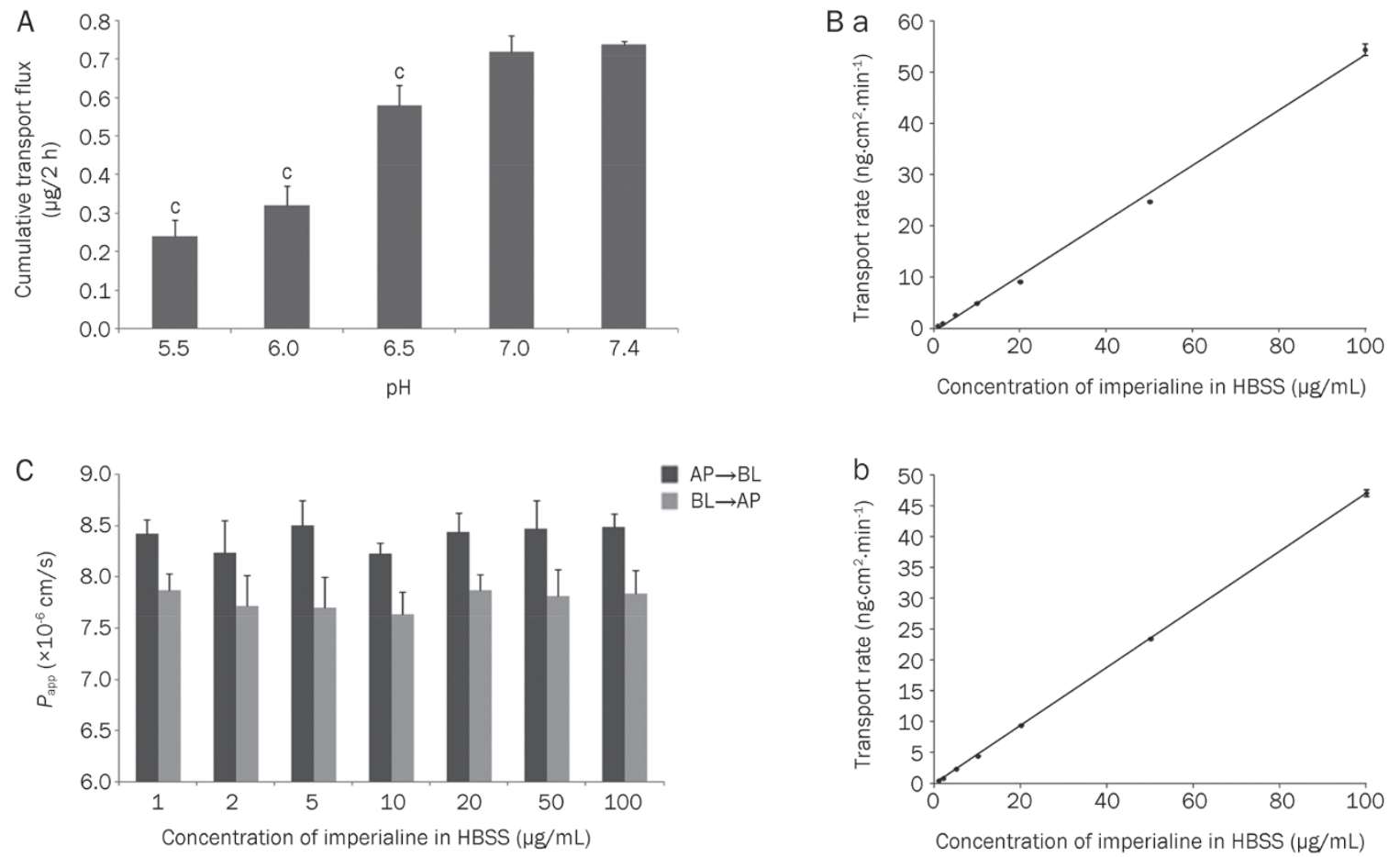

Figure 4. (A) The effect of $\mathrm{pH}$ on imperialine in Caco-2 cell monolayer transport $(n=3):{ }^{\mathrm{c}} \mathrm{P}<0.01$ compared with the $\mathrm{pH} 7.4$ group. (B) The transport rate of imperialine across the Caco- 2 cell monolayer $(n=3)$ : (a) from the AP to the BL side and (b) from the BL to the AP side. (C) $P_{\text {app }}$ of imperialine across the Caco-2 cell monolayers ( $n=3)$.

Table 3. Effect of P-gp and NPC1L1 inhibitors on the transport of imperialine across Caco-2 cell monolayers. All results are the mean of measurements from three replicates. ${ }^{a}$ Mean $\pm S D$. ${ }^{b} P$, two-tailed $t$-test.

\begin{tabular}{|c|c|c|c|c|c|c|c|c|c|c|}
\hline \multirow{2}{*}{$\begin{array}{l}\mathrm{C} \\
(\mu \mathrm{g} / \mathrm{mL})\end{array}$} & \multicolumn{5}{|c|}{$\mathrm{AP} \rightarrow \mathrm{BL} P_{\text {aap }}\left(\times 10^{-6} \mathrm{~cm} / \mathrm{s}\right)$} & \multicolumn{5}{|c|}{$\mathrm{BL} \rightarrow \mathrm{AP} P_{\text {aap }}\left(\times 10^{-6} \mathrm{~cm} / \mathrm{s}\right)$} \\
\hline & Non $^{a}$ & $\operatorname{Ver}^{\mathrm{a}}$ & $P^{\mathrm{b}}$ & $\mathrm{Eze}^{\mathrm{a}}$ & $P^{\mathrm{b}}$ & Non $^{a}$ & $\operatorname{Ver}^{\mathrm{a}}$ & $P^{\mathrm{b}}$ & Eze $^{a}$ & $P^{\mathrm{b}}$ \\
\hline 2 & $8.81 \pm 0.81$ & $8.23 \pm 0.48$ & 0.35 & $8.98 \pm 0.45$ & 0.36 & $7.72 \pm 0.45$ & $6.70 \pm 0.83$ & 0.18 & $7.72 \pm 0.92$ & 0.80 \\
\hline 10 & $8.40 \pm 0.73$ & $8.22 \pm 0.10$ & 0.31 & $8.50 \pm 0.91$ & 0.31 & $7.63 \pm 0.22$ & $7.76 \pm 0.69$ & 0.50 & $7.35 \pm 0.75$ & 0.90 \\
\hline 50 & $8.19 \pm 0.32$ & $8.47 \pm 0.42$ & 0.60 & $8.22 \pm 0.11$ & 0.66 & $7.81 \pm 0.26$ & $7.38 \pm 0.42$ & 0.20 & $7.60 \pm 0.56$ & 0.58 \\
\hline
\end{tabular}

Abbreviations: Ver, for verapamil; Eze, for Ezetimibe.

\section{Absorptive characteristics of imperialine in rats}

The modified gravimetric method was applied in a singlepass intestinal perfusion model. The cumulative absorption of imperialine $(1,5$, and $10 \mu \mathrm{g} / \mathrm{mL})$ in different intestinal segments is illustrated in Figure $5 \mathrm{~A}$, and a series of parameters obtained in various segments are summarized in Table 4 . The results obtained showed that with increasing concentrations, the absorption of imperialine increased, and the saturation was not manifested at high concentrations. The imperialine absorption in the different segments varied with a constant imperialine concentration, with the colon displaying the highest level of absorption. In the same intestinal segments, the $P_{\text {eff }}$ or $K_{\mathrm{a}}$ was basically consistent $(P>0.05)$ when imperialine concentration varied. This supported the presupposition that passive diffusion was the dominant process in imperialine absorption. In addition, adding either the P-gp or the $\mathrm{NPC}_{1} \mathrm{~L}_{1}$ inhibitor did not exert significant differences over absorption without inhibitors (Figure 5B and 5C).

\section{Discussion}

The oral bioavailability of imperialine has been previously reported to be relatively high ${ }^{[4]}$. Based on this observation, the compound's biopharmaceutical features were investigated. To clarify the relationship between the molecular properties and the absorption characteristics of imperialine, we determined the compound's physicochemical properties, including its solubility, oil/water partition coefficient and ionization constant. In addition, the in vitro uptake and transport mechanisms were also investigated using Caco-2 cells, and in situ single-pass intestinal perfusion was performed on intestinal segments.

In the current study, we quantitatively proved imperialine's aqueous solubility and oil/water partition coefficient in pure water and PBS at different $\mathrm{pH}$ values. The compound demon- 
Table 4. Absorption parameters of imperialine in each intestinal segment. All results are the mean of measurements from five animals. Values are expressed as the mean \pm SD.

\begin{tabular}{|c|c|c|c|c|}
\hline \multirow{2}{*}{$\begin{array}{c}\text { C } \\
(\mu \mathrm{g} / \mathrm{mL})\end{array}$} & \multirow[b]{2}{*}{ Segment } & \multicolumn{3}{|c|}{ Absorption parameters } \\
\hline & & $\begin{array}{c}P_{\text {eff }} \\
\left(\times 10^{-3} \mathrm{~cm} / \mathrm{min}\right)\end{array}$ & $\begin{array}{c}K_{a} \\
\left(\times 10^{-2} / \min \right)\end{array}$ & $\begin{array}{c}M_{\mathrm{a}} \\
\left(\mu \mathrm{g} / \mathrm{cm}^{2}\right)\end{array}$ \\
\hline \multirow[t]{4}{*}{1} & Duodenum & $3.68 \pm 0.81$ & $5.19 \pm 0.92$ & $0.28 \pm 0.06$ \\
\hline & Jejunum & $3.63 \pm 0.44$ & $4.84 \pm 0.92$ & $0.26 \pm 0.08$ \\
\hline & Ileum & $8.31 \pm 1.10$ & $9.51 \pm 0.64$ & $0.43 \pm 0.10$ \\
\hline & Colon & $15.13 \pm 1.48$ & $17.44 \pm 2.94$ & $0.79 \pm 0.02$ \\
\hline \multirow[t]{4}{*}{5} & Duodenum & $3.89 \pm 0.75$ & $4.62 \pm 1.26$ & $1.51 \pm 0.40$ \\
\hline & Jejunum & $2.91 \pm 0.53$ & $3.22 \pm 0.58$ & $1.05 \pm 0.14$ \\
\hline & Ileum & $8.54 \pm 0.52$ & $9.39 \pm 1.82$ & $2.22 \pm 0.28$ \\
\hline & Colon & $14.00 \pm 1.64$ & $16.58 \pm 1.65$ & $3.22 \pm 0.34$ \\
\hline \multirow[t]{4}{*}{10} & Duodenum & $4.41 \pm 0.69$ & $6.51 \pm 1.95$ & $2.22 \pm 0.74$ \\
\hline & Jejunum & $3.84 \pm 0.95$ & $4.90 \pm 0.66$ & $3.66 \pm 0.51$ \\
\hline & Ileum & $9.53 \pm 0.93$ & $10.68 \pm 1.27$ & $3.83 \pm 0.45$ \\
\hline & Colon & $15.16 \pm 2.79$ & $10.68 \pm 1.27$ & $7.65 \pm 0.22$ \\
\hline
\end{tabular}

strated a relatively weak alkalinity, with a $\mathrm{p} K_{\mathrm{a}}$ of $8.467 \pm 0.028$.

Furthermore, the uptake and transepithelial transport of imperialine in the Caco-2 cell model exhibited a pH-dependent effect. The main reason for this result was that most of the imperialine existing under physiological conditions, ie, at $\mathrm{pH} 7$ or above, was in the non-ionized form, which would enhance its absorption despite the relatively low solubility of the compound. In other words, the permeability was more important than the solubility in this case. In addition, we observed that in the Caco-2 cells, both uptake and transport were concentration-dependent without saturation phenomenon in the selected concentration range, implying that passive membrane diffusion was the main mode of transport. The absorptive $P_{\text {app }}$ was measured as $(8.39 \pm 0.12) \times 10^{-6} \mathrm{~cm} / \mathrm{s}$ and the secretory $P_{\text {app }}$ was $(7.78 \pm 0.09) \times 10^{-6} \mathrm{~cm} / \mathrm{s}$, which was above the recognized threshold value of $2 \times 10^{-6} \mathrm{~cm} / \mathrm{s}$ for completely absorbed drugs in Caco-2 monolayers ${ }^{[19,}{ }^{20]}$, and was consistent with the relatively high bioavailability of imperialine noted in a previous pharmacokinetic study ${ }^{[4]}$. As with the former result, the
A a

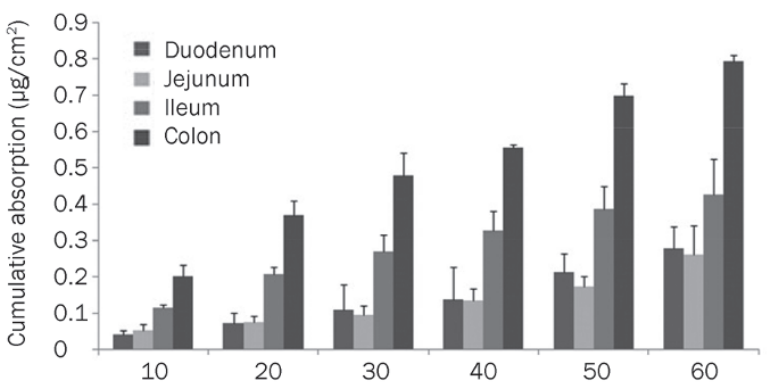

b

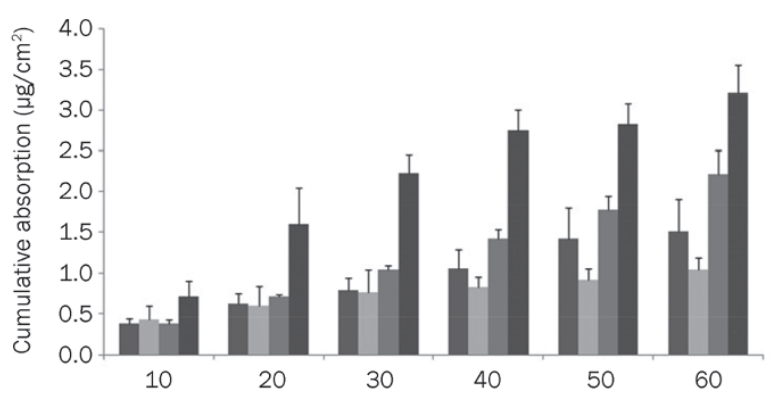

C

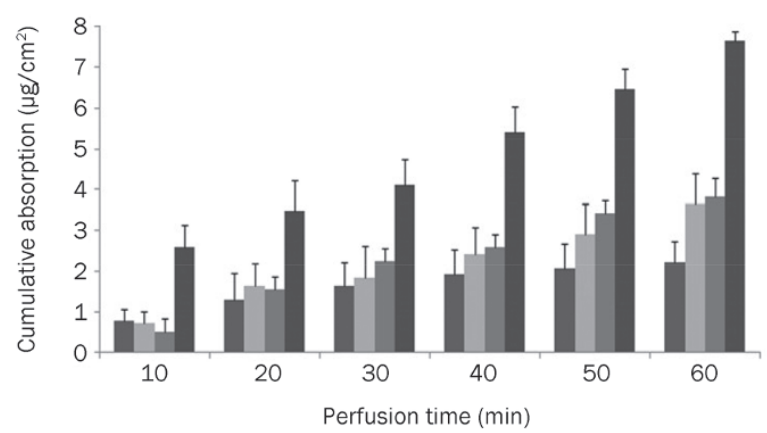

B

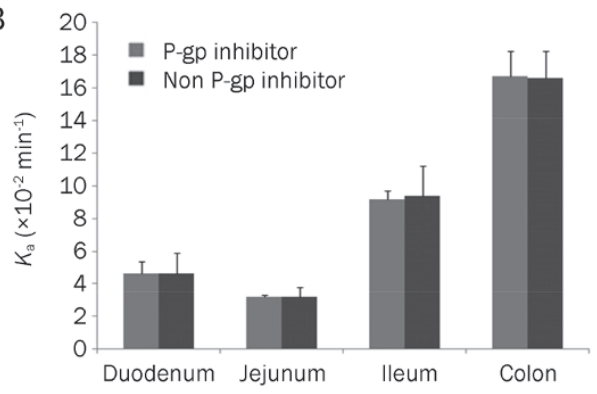

C

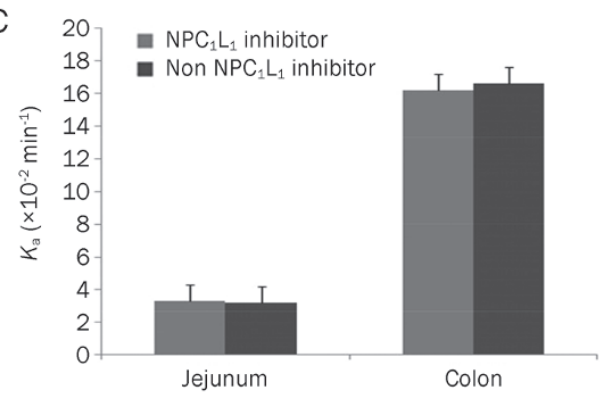

Intestinal segments

Figure 5. (A) Cumulative absorption of different concentrations of imperialine in rat intestinal segments $(n=5)$. The concentration of imperialine in the perfusate was (a) $1 \mu \mathrm{g} / \mathrm{mL}$, (b) $5 \mu \mathrm{g} / \mathrm{mL}$, and (c) $10 \mu \mathrm{g} / \mathrm{mL}$. (B) P-gp inhibition study in rat intestinal segments $(n=5)$; $(C) N P C_{1} \mathrm{~L}_{1}$ inhibition study in rat intestinal segments $(n=5)$. 
inhibitory studies suggested that neither P-gp nor $\mathrm{NPC}_{1} \mathrm{~L}_{1}$ was involved in the transport of imperialine. Because Verapamil is a known inhibitor of P-gp and Ezetimibe is a known inhibitor of $\mathrm{NPC}_{1} \mathrm{~L}_{1}$, they did not limit the oral absorption of imperialine. The isomer of imperialine, peiminine (ie, verticinone), was also found to be non-P-gp-regulated ${ }^{[21]}$. As the substrate always showed structural similarity, we firmly believed this negative result.

To further investigate the absorptive characteristics of imperialine, we performed single-pass intestinal perfusion assays combined with a modified gravimetric method in an in situ model. Consistent with the results obtained using Caco- 2 cells in vitro, in a certain segment, both $P_{\text {eff }}$ and $K_{\mathrm{a}}$ were basically consistent, supporting the conclusion that passive diffusion was the dominant process for imperialine absorption. For a given concentration, the absorption differed among the segments, with the colon absorbing the most imperialine. This may be due to the higher $\mathrm{pH}$ (approximately 7.4) in the colon than in the other segments, which increases the non-ionized form of imperialine and thereby enhances the imperialine permeability across the intestinal mucosa. The inhibition study again supported the prediction that imperialine was not the substrate of P-gp and that steroid compounds would not affect the absorption of imperialine through $\mathrm{NPC}_{1} \mathrm{~L}_{1}$.

\section{Conclusion}

We have investigated the biopharmaceutical properties of imperialine, from its physicochemical properties to its in vitro and in situ behavior. The results presented in the current study showed that the $\mathrm{pH}$ of the medium affects the uptake and transport of imperialine, although the temperature does not. Furthermore, passive membrane diffusion dominated the absorptive and transport behavior of imperialine. Neither absorption nor secretion was mediated by $\mathrm{P}$-gp or $\mathrm{NPC}_{1} \mathrm{~L}_{1}$. These results provide a better understanding of the intestinal absorption of imperialine.

\section{Acknowledgements}

We are grateful for support from the National Basic Research Program of China (№ 2013CB932504) and the National Natural Science Foundation of China (№ 81130060).

\section{Author contribution}

Zhi-rong ZHANG and Qing LIN designed the research; Qing LIN, Li-qin LING, and Ling GUO performed the research; Zhirong ZHANG, Tao GONG, and Xun SUN contributed new reagents or analytic tools; Qing LIN and Ling GUO analyzed the data; and Qing LIN wrote the paper.

\section{Supplementary information}

Supplementary information is available at the Acta Pharmacologica Sinica's website.

\section{References}

1 Ministry of Public Health of the People's Republic of China. Pharmacopoeia of the people's republic of China. Beijing: China Medical
Science Press 2010. vol I, p 34.

2 Wang D, Zhu J, Wang S, Wang X, Ou Y, et al. Antitussive, expectorant and anti-inflammatory alkaloids from Bulbus Fritillariae Cirrhosae. Fitoterapia 2011; 82: 1290-4.

3 Liu G, Franssen E, Fitch MI, Warner E. Patient preferences for oral versus intravenous palliative chemotherapy. J Clin Oncol 1997; 15: $110-5$.

4 Lin Q, Zhang Q, Song X, Gong T, Sun X, Zhang Z, et al. Novel LC-MS/ MS method for analyzing imperialine in rat plasma: development, validation, and application to pharmacokinetics. J Chromatogr B 2013; 938: 51-9.

5 Winne D. Shift of pH-absorption curves. J Pharma Biopharm 1977; 5: 53-94.

6 Artursson P, Palm K, Luthman K. Caco-2 monolayers in experimental and theoretical predictions of drug transport. Adv Drug Deliv Rev 2001; 46: 27-43.

7 Dai JY, Yang JL, Li C. Transport and mrtabolism of flavonoids from Chinese herbal remady Xiaochaihu-tang across human intestinal caco-2 cell monolayers. Acta Pharmacol Sin 2008; 29: 1086-93.

8 Gan LSL, Thakker DR. Applications of the Caco-2 model in the design and development of orally active drugs: elucidation of biochemical and physical barriers posed by the intestinal epithelium. Adv Drug Deliv Rev 1997; 23: 77-98.

9 Zhang X, Qiu F, Jiang J, Gao C, Tan Y. Intestinal absorption mechanisms of berberine, palmatine, jateorhizine, and coptisine: involvement of P-glycoprotein. Xenobiotica 2011; 41: 290-6.

10 Park SW. Intestinal and hepatic niemann-Pick C1-Like 1. Diabetes Metab J 2013; 37: 240-8.

11 Rodrigues AC, Curi R, Genvigir FDV, Hirata MH, Hirata RDC. The expressions of efflux and uptake transporters are regulated by statins in Caco-2 and HepG2 cells. Acta Pharmacol Sin 2009; 30: 956-64.

12 Högerle ML, Winne D. Drug absorption by the rat jejunum perfused in situ. Naunyn Schmiedeberg Arch Pharmacol 1983; 322: 249-55.

13 Shiau YF, Fernandez P, Jackson MJ, McMonagle S. Mechanisms maintaining a low-pH microclimate in the intestine. Am J Physiol 1985; 248: G608-17.

14 Zhang QY, Wikoff J, Dunbar D, Kaminsky L. Characterization of rat small intestinal cytochrome P450 composition and inducibility. Drug Metab Dispos 1996; 24: 322-8.

15 Chiou WL, Barve A. Linear correlation of the fraction of oral dose absorbed of 64 drugs between humans and rats. Pharm Res 1998; 15: $1792-5$.

16 Ministry of public health of the people's republic of China. Pharmacopoeia of the people's republic of China. Beijing: China Medical Science Press 2010; vol II (Appendix), p 176-7.

17 Takács-Novák K, Avdeel A. Interlaboratory study of log P determination by shake-flask and potentiometric methods. J Pharm Biomed Anal 1996; 14: 1405-13.

18 Natoli M, Leoni BD, D’Agnano I, D'Onofrio M, Brandi R, Arisi I, et al. Cell growing density affects the structural and functional properties of Caco-2 differentiated monolayer. J Cell Physiol 2011; 226: 1531-43.

19 Artursson P, Karlsson J. Correlation between oral drug absorption in humans and apparent drug permeability coefficients in human intestinal epithelial (Caco-2) cells. Biochem Biophys Res Commun 1991; 175: 880-5.

20 Artursson P, Palm K, Luthman K. Caco-2 monolayers in experimental and theoretical predictions of drug transport. Adv Drug Deliv Rev 2012; 64: 280-9.

21 Guan ZY, Zhang LH, Chen LH, Zhu WF, Liu HN. Rat intestinal absorption trait of peimine and peiminine in Thunberg fritillary bulb extract. Yao Xue Xue Bao 2013; 48: 1836-43. 